\title{
The Role of Language and Cultural Orientation in Guilt and Shame Experienced by Bilingual Female Speakers
}

\author{
Khadija El Alaoui \\ Maura A. E. Pilotti \\ Huda Mulhem \\ Ebtesam Ahmad Tallouzi \\ Mona Mohammed Abdullah Al Mqbas
}

College of Humanities and Social Sciences, Prince Mohammad Bin Fahd University, Al Khobar, Saudi Arabia

Note: Authors have contributed equally to the research. Correspondence concerning this article should be addressed to the corresponding author, Maura A. E. Pilotti, Prince Mohammad Bin Fahd University, P.O. Box 1664, Al Khobar 31952, Kingdom of Saudi Arabia. E-mail: mpilotti@pmu.edu.sa. Office phone: +966535166572.

\section{Abstract}

In the present experiment, we asked two interrelated questions: (a) whether the dominant cultural orientation of bilingual female speakers (collectivism versus individualism), as promoted by the language currently in use (Arabic versus English), would lead respondents to treat guilt and shame as distinct or largely similar emotions; and (b) whether the affective profiles of guilt and shame would replicate or diverge from those attributed by the existing literature to members of individualistic cultures whose primary language is English. In the experiment, bilingual female speakers $(n=182)$ completed a measure of cultural self-orientation, recalled an experience of either guilt or shame, and then rated the emotion recalled on descriptive scales. They accomplished these tasks by relying on either English or Arabic. Although the two emotions were narrowly differentiated, shame was found to be more dominant than guilt. Shame also yielded a greater focus on oneself. Contrary to the expectation of higher emotionality for the first language 
(Arabic), language differences mostly underlined differences in participants' focus of attention, either others or oneself. These findings are compared with those reported in the cross-cultural literature, and implications are discussed.

Keywords: guilt, shame, language, culture

Both English and Arabic contain distinct terms for shame (al-'ar; العار) and guilt (al-dhanb; الذنب ). A review of the literature on the meaning of these words in English, mostly produced by scholars from the Western world (i.e., North America and Western Europe), uncovers a collection of slightly diverse definitions, each underscoring their differences and similarities. Discrepancies exist in both the scholarly literature and the ordinary usage of these terms, raising the obvious question of whether shame and guilt in the everyday life of different cultures are essentially shades of the same affective phenomenon. For instance, although evidence exists that the events that elicit shame tend to be more ambiguous and surprising (Wicker, Payne, \& Morgan, 1983), the specific events that people cite as triggers of either shame or guilt can be similar, including cheating, lying, and stealing (Tangney, 1992; Tangney, Miller, Flicker, \& Barlow, 1996). Stipek (1998) notes that these terms are generally used to refer to situations where personal traits or actions and their outcomes are judged against personal or social standards; failure to meet personal standards is thought to result in the experience of shame, whereas failure to conform to social standards (i.e., transgression) is thought to result in the experience of guilt (see also Ausubel, 1955; Campos \& Barrett, 1984; Izard, 2013; Lewis, 1971; Tangney, Burggraf, \& Wagner, 1995). However, Bierbrauer (1992) refers to shame as a defensive response to the criticism of others, which stems from one's fears of rejection and retraction of social support, whereas he treats guilt as self-criticism arising from failures to meet internalized standards. Gilbert (2003) takes an evolutionary perspective to differentiate between these two emotions; he argues that shame derives from a threat to the self and the need to be acceptable to others, and thus possesses an inward focus and essentially is an epiphenomenon of a self-defensive mode. Guilt instead originates from one's responsibility toward others, possesses an outward focus, and is related to competencies for altruism. Other scholars, such as Wong and Tsai (2007), suggest the opposite, that shame involves being evaluated negatively by either real or imagined others (i.e., being focused on others and thus possessing an outward orientation), whereas guilt involves being evaluated by oneself negatively (i.e., being focused on oneself and thus possessing an inward orientation).

Perhaps the most popular characterization of shame and guilt experiences as being fundamentally different from each other is less about the specific undesirable behavior or transgression a person has exhibited, but rather the person's attributional focus (Lewis, 1971). Namely, shame is said to involve the 
recognition of a flawed self who is both the agent of an undesirable action (e.g., "I cannot believe I did that") and the object of analysis and condemnation (e.g., "I am unworthy"). In this form of self-analysis, the audience is the self who is expressing a negative judgment for the person he/she has become. Thus, one's inadequacies are exposed, though a real audience may or may not be present. Instead, guilt is said to involve the recognition of a flawed action that reflects negatively on the self, but the self is not the central object of the analysis and related condemnation. Namely, a person feels criticized for what he/she has done. The presumed different attentional focus that characterizes guilt and shame leads to the assumption that shame motivates the person who experiences it to conceal or escape, whereas guilt inspires the person who experiences it to engage in actions that repair (e.g., apologies, confessions) and undo the damage that they have caused (Wollheim, 1999). Shame calls for others (either real or imagined) to forget what was done, whereas guilt asks others to forgive. Although most empirical evidence, largely from the Western world, has supported Lewis's definition of these two self-conscious emotions as substantially different in the manner in which they are felt (Tangney et al., 1996; Wicker et al., 1983), evidence of undifferentiation also exists (Nelissen, Breugelmans, \& Zeelenberg, 2013; Smith \& Ellsworth, 1985; 1987). For instance, Wicker and colleagues (1983) found that differences in the ratings of the two emotions on several phenomenological dimensions were mostly of magnitude rather than of valence. Tangney and colleagues (1996) also found no evidence of the distinction between focus on a flawed self and focus on one's undesirable actions for shame and guilt, respectively. Even Lewis reported that shame and guilt "tend to fuse with each other" (1971, p. 35) and, as such, they are "easily confused with each other" (p. 37).

\section{Self-Conscious Emotions and Culture}

Cultures are loose patterns of attitudes, beliefs, schemas, categories, norms, roles, and values that are shared by individuals who speak a common language and generally live in a given territory during a particular time period (Triandis, 1989; 1995). At the individual level, interiorized cultures shape the orientation of the self towards others (i.e., dependent versus independent), the relative importance of personal versus group goals, the extent to which behavior is assumed to result from dispositional versus situational determinants, and one's emphasis on communal relationships versus equitable exchanges (Kitayama \& Markus, 1995).

An interiorized culture can shape not only perceptions of the self and others, but also emotional experiences (Hoffman, Lau, \& Johnson, 1986; Wallbott \& Scherer, 1995). A relevant dimension along which cultural patterns can 
be described is whether their predominant orientation is collectivistic or individualistic (Triandis, Chan, Bhawuk, Iwao, \& Sinha, 1995). As shame and guilt are self-conscious emotions, evidence of differences between shame and guilt gathered from participants whose cultural orientation is individualism may not apply to individuals whose cultural orientation is collectivism. The main reason is that such differences refer to an independent and stable self that is bounded, separate from others, and whose orientation, at any given point in time, can be clearly classified as either internal or external. In collectivism, the self and others are less clearly detached and the boundaries of one's personal space are more permeable (Feghali, 1997). Because others' thoughts and feelings are not less important than one's own thoughts and feelings, the self is much more susceptible to situational forces, and thus variability of the self rather than stability across time is viewed as normative (Wong \& Tsai, 2007).

Even though cross-cultural studies on self-conscious emotions exist, the bulk of empirical evidence has come from comparisons involving the collectivistic cultures of east Asia (e.g., China and Japan) and the individualistic culture of the United States (Wong \& Tsai, 2007). Empirical evidence from the collectivistic cultures of the Arabian Peninsula in general, and from the culture of the Kingdom of Saudi Arabia in particular, is missing. Besides the uncertainty that surrounds scholarly attempts to elucidate the meanings of guilt and shame, the ordinary use of these and other emotional words is notoriously imprecise. Thus, the existence of distinct words for shame and guilt in the Arabic language, as in the English language, does not automatically support the postulation that the referent emotions are indeed treated differently in everyday life. Laypersons in Saudi Arabia may use the terms shame and guilt interchangeably, thereby disregarding semantic differences recognized by some Western scholars (see Panayiotou, 2006).

Saudi culture has been described as predominantly collectivistic/interdependent, whereas the culture of the United States, where most of the evidence on guilt and shame has been collected, has been labeled individualistic/independent (Hofstede, 2001; Hofstede \& Hofstede, 2005; Kitayama, Markus, \& Matsumoto, 1995; Markus \& Kitayama, 1991). The collectivistic perspective (also called allocentrism) regards the self as interdependent because a person's identity is shaped by relationships and embodies group cohesion, loyalty to and solidarity with one's family, tribe, or nation. The individualistic perspective (also called idiocentrism), however, regards the self as capable of existing irrespective of one's ingroup and thus a person's identity is driven by intense self-enhancing tendencies, desires to stand on one's own feet, and persistent efforts towards personal achievement.

According to Kitayama, Mesquita, and Karasawa (2006), cultural patterns can evoke and foster different sets of emotions which people spontaneously categorize and recognize for their valence and social orientation. Socially engag- 
ing emotions, irrespective of whether they are positive or negative, are defined as those that reflect and nurture an interdependent self, whereas socially disengaging emotions are defined as those that reflect and nurture an independent self. Evidence exists that people from collectivistic cultures, which emphasize interdependence and engagement (e.g., Japanese nationals), experience more often and more intensely engaging emotions in naturally occurring situations, whereas people from individualistic cultures, which emphasize independence and disengagement (e.g., USA nationals), experience higher frequency and intensity of disengaging emotions (Kitayama, Marcus, \& Kurokawa, 2000; Kitayama et al., 2006).

Kitayama and colleagues (2006) do not differentiate between guilt and shame. Both are classified as negative engaging emotions. The few studies designed to test cross-cultural differences in shame and guilt experiences have sought to see whether individualistic and collectivistic cultures use guilt and shame differently for social control. For instance, if one assumes that shame is a threat to the self, members of collectivistic societies may be expected to experience greater shame reactions than those of individualistic societies because the boundaries between the self and others, as well as those between public and private selves (Feghali, 1997; Hall, 1966), are less well-defined. The findings of these studies have been inconclusive. Cross-cultural evidence from the collectivistic culture of China and the individualistic culture of the United States has not shown differences in the intensity of either emotion for transgressions involving the self, but merely greater intensity for transgressions carried out by members of one's kinship (Stipek, 1998). Ghorbani and Liao (2014) report that Chinese people who were born and raised in China experience both more guilt and shame than Chinese people socialized in an individualistic culture (e.g., who were born in Canada or had moved to Canada at an early age). Marsella, Murray, and Golden (1974) find that Chinese immigrants experience stronger shame than individuals of European descent. Bierbrauer (1992) reports that people of Lebanese and Kurdish descent, who exhibit a collectivistic orientation, experience greater shame and guilt than Germans, who exhibit an individualistic orientation. Johnson and colleagues (1987) relate that Koreans, who express a collectivistic orientation, experience less shame and guilt than participants from Taiwan, who also express a collectivistic orientation, as well as American participants, who exhibit an individualistic orientation. The same research reports a high degree of cross-cultural agreement among all groups on the specific undesirable actions that may trigger either emotion and on the severity attributed to these actions.

It is clear that the available cross-cultural evidence raises the question of whether Saudi nationals would exhibit a different affective profile for each of these two emotions, and if so, whether the contents of each profile would differ from the published experiences reported by those whose cultural orienta- 
tion is individualism. Anecdotal evidence and scholarly observations, rather than solid empirical evidence, suggest that shame and guilt should be experienced as different affective patterns by Saudi nationals. For instance, Sharabi (1977) whose work focuses on urban, middle-class Muslim families, asserts that shame is at the core of the childrearing practices of educational, religious, and family institutions. Specifically, he states that the child "is made to feel ashamed because others see him as having acted wrongly, not because he inwardly regrets having done wrong and judges himself accordingly" (p. 248). In his review of Saudi law, Souryal (1987) states that the misbehavior of a Saudi is thought to bring shame to his/her family and entire tribe, thereby tainting the sharaf (honor) of all parties involved. If shame is viewed as a key aspect of punishment, guilt has a redeeming quality. Namely, according to traditional customs, offenders may be offered pardon if they admit their guilt and repent before they are brought to account for their deeds.

Differences between shame and guilt in Saudi Arabia are also expected if credence is given to the controversial distinction between shame cultures, which allegedly exercise social control primarily by means of external sanctions, and guilt cultures, which purportedly exercise social control mostly by means of their members' internalized sanctions (Scheff, 1994; Wallbott \& Scherer, 1995). This distinction, which has been criticized for its value judgment and mixed support (Ghorbani \& Liao, 2014; Panayiotou, 2006; Scheff, 1994), has been often used to refer to the relative importance of each emotion in collectivistic cultures, where shame is allegedly dominant, and in individualistic cultures, where guilt is purportedly dominant. Furthermore, if any support is found for it, comparisons mostly include the collectivistic cultures of China or Japan and the individualistic cultures of the United States or western Europe (Fessler, 2004; Ho, Fu, \& Ng, 2004; Li, Wang, \& Fischer, 2004; Marsella, Murray, \& Golden, 1974). Saudi Arabia is a state where traditions, religiously colored and developed in the harsh physical environment of the desert and steppe, are placed alongside economic and social forces that emulate Western lifestyles, mostly grown in urban centers and propelled by a rapidly expanding youth population (Ménoret, 2005; Murphy, 2012). Thus, forms of collectivism in Saudi Arabia and in east Asia may not be isomorphic. Indeed, applying the label of collectivism to Saudi Arabia may overlook the cultural complexities of that country, which need to be addressed if sensible predictions are to be formulated. For example, Saudi Arabia and the United States share the dimension of verticality (i.e., they envision an individual who exists within a hierarchical social order; Singelis, Triandis, Bhawuk, \& Gelfand, 1995; Triandis, 1995). Additionally, Saudi Arabia, which came into existence as a nation almost a century ago, has gone through a series of social and economic changes (Al-Ghadhami, 2013, 2014; Omar, 2014): (1) a pre-oil period, characterized by tribal traditions, 
(2) a modernization phase (circa 1940-1960), characterized by the opening to the West and its economic and cultural influences, (3) the awakening phase (circa 1980-2000), defined by a return to traditional religious values, and (4) the present characterized by attempts at adjusting to two conflicting forces. On one side, Saudi Arabia has faced the pressure to modernize its economic, social, educational, and governmental structures, and has done so mostly by emulating Western models of consumerism (Assad, 2006); on the other side, it has struggled to maintain traditions based on vertical collectivistic values and institutionalized religious doctrine. Most importantly, the forces promoting traditional values and customs have encouraged commitment to one's kinship, thereby emphasizing solidarity and cohesion towards one's group, and competition towards other groups, thereby underscoring one's honor and reputation by comparison with others. Competition is a key aspect of vertical individualism, which defines American culture (Singelis et al., 1995). Not surprisingly, a recent study by Maddux, San Martin, Sinaceur, and Kitayama (2011) has shown that contrary to evidence obtained in other collectivistic cultures, the frequency with which Saudi nationals experience disengaging emotions is comparable to that of Americans. The important caveat of this study is that participants were not only Saudi nationals, but also Arabic-English bilingual speakers who responded to a series of questionnaires and scales written in English (i.e., their second language). A bilingual speaker's use of English may further promote thinking of oneself as independent rather than interdependent. If so, the findings of Maddux and colleagues may be accounted for by the impact of language as a vehicle of culture.

It is important to note that most of the cross-cultural research devoted to the study of self-conscious emotions has involved comparisons between groups of individuals. An alternative approach to the study of cultural influences originates from the phenomenon of "frame switching", which refers to the ability of bilingual individuals who have been socialized in two cultures to shift between interiorized cultural frames in response to environmental cues and demands (LaFromboise, Coleman, \& Gerton, 1993; Hong, Morris, Chiu, \& Benet-Martínez, 2000). This approach relies on the assumption that internalized cultures, as much as languages, do not necessarily blend, but rather coexist in the bilingual mind as separate constructs that become accessible at different times, depending on the demands and cues of the surrounding environment. Namely, from a functional viewpoint, possessing a culture or a language is analogous to possessing any of the mental constructs that define human cognition in the sense that it does not entail relying on each one continuously. Hence, cross-cultural comparisons (Hong et al., 2000) can be performed on individuals who are fluent speakers of two languages and thus can be considered vehicles of two distinct cultures. 
One powerful cue that is capable of triggering frame switching is language (Trafimow, Silverman, Fan, \& Law, 1997). In this regard, a language "is 'a veil' over the reality of the culture in which it is used, involving an agreement of its users about what there is to be seen and how it should be seen" (Kim, 1988, p. 89). Exposure to two cultural frames of reference, the traditional vertical collectivistic culture of the Arab tradition and the vertical individualistic culture of the Western world, can be assumed to be particularly substantial in Saudi Arabic-English bilingual speakers. In fact, as speakers of two languages, they may be accustomed to crossing linguistic and cultural boundaries, and perhaps can identify with each of the two sides of such boundaries (El Alaoui, Mulhem, Pilotti, Aamir, \& Ahmad Tallouzi, 2017; Hong et al., 2000). Thus, bilingual speakers may be the ideal population for cross-linguistic/cultural comparisons because they are capable of subjectively experiencing emotions in each language through its corresponding culture (Panayiotou, 2006).

The timing of language acquisition is a factor in evaluating the emotional understanding of words. Sequential bilingual speakers are individuals who have acquired their second language after their first language. Previous studies of sequential bilingual speakers report that they experience their second language as less emotional than their first language. Namely, although they may be proficient in the second language, and thus appreciate the emotional connotation of its words, they do not sense such words as intuitively and automatically as those in their first language (Opitz \& Degner; 2012; Pavlenko, 2008). As a result, for instance, they feel less inhibited to talk about embarrassing topics in their second language (Bond \& Lai, 1986). As adults, they remember childhood reprimands spoken in their first language with greater emotional resonance and stronger arousal than equivalent reprimands spoken in the second language (Anooshian \& Hertel, 1994; Harris, Aycicegi, \& Gleason, 2003).

Differences in emotional responsiveness are generally attributed to both the timing and the context of acquisition. The vocabulary of the first language tends to be learned in the context of early relationships through which speakers initially experience the full range of basic human emotions (Schrauf, 2000). The vocabulary of the second language is learned in the context of later social relationships, which tend to develop at work and in school, that is, in settings where codified formalities regulate emotional expression. As a result, the second language is likely to reflect the speaker's emotional control and distance (Bond \& Lai, 1986; Dewaele \& Pavlenko, 2002; Ervin, 1964). It follows that sequential bilingual speakers can offer valuable information regarding not only the impact of cultural orientation on the experience of self-conscious emotions, but also the extent to which the age of acquisition of the language in use may modulate the experience. 


\section{Overview of the Present Study}

In the present study, we examined the extent to which the reported differences in the experience of guilt and shame obtained from individualistic cultures, are reflected in individuals whose dominant cultural orientation, evoked by the language in use, is either collectivistic or individualistic. The approach used was not to compare groups of individuals who pertain to different cultural and/ or national groups, but rather to examine self-reports of guilt and shame produced by individuals who are capable of frame switching. As discussed earlier, in investigations whose data involve people who possess an individualistic orientation, a certain degree of uncertainty exists in the attributes of self-conscious emotions proposed by different scholars. Furthermore, empirical support is not always consistent across different studies. Thus, in the absence of definitions that rely on both widespread consensus and solid support, the hypotheses of the present study are phrased to enunciate differences rather than predict specific patterns, and comparisons between the study's findings and those in the literature are guided by a search for the best fit.

At its core, the study relied on the basic assumption that raw physiological changes in arousal are filtered through and evaluated by the cultural orientation engaged by the speaker's language in use (Arabic or English). Participants were sequential bilingual speakers to ensure that the independent effects of language as a vehicle of cultural orientation and of language as modulator of emotional intensity could be detected. Furthermore, bilingual young female residents of Saudi Arabia were chosen because of the dearth of direct empirical evidence regarding their experience of self-conscious emotions, and because of their documented ability to use frame switching (El Alaoui, Mulhem, Pilotti, \& al-Mqbas, 2017; El Alaoui et al., 2017). Surprisingly, studies on self-conscious emotions in nonclinical populations have largely overlooked the unique status of young women in Saudi Arabia, who are the recipients of onerous restrictions and are the objects of intense debates depicting them as either the "Trojan horse of Westernization" or the "last bastion of religion" (Ménoret, 2005, p. 175). Making observations as a French civil servant working in Riyadh, Ménoret writes that "not a week goes by without several men taking up their pen and writing in the press or on the internet" about Saudi women in either one of the two roles. The mutually exclusive categories to which women have been assigned are unlikely to reflect the complexities of their daily existence in a society where purity of tradition is placed alongside economic forces that demand social changes. At the same time, however, the constructed dichotomy exposes men's suspicion that women, especially young ones, may hold identities underscoring both Western values (e.g., independent self) and traditional customs (e.g., interdependent self). Ironically, this suspicion is supported by studies in 
which young females have been found to have preserved an interdependent self-construct (Dwairy, Achoui, Abouserie, \& Farah, 2006), and also to switch between independent and interdependent self-constructs, depending on the language in use (El Alaoui et al., 2017).

Two key hypotheses guided the present investigation: First and foremost, it was hypothesized that if a language is a vehicle of cultural orientation and also a modulator of emotional experiences, an interaction of emotional scenario and language would be observed. Namely, the attributes of the emotional patterns of shame and guilt reported by Arabic-English bilingual speakers given instructions and scales in Arabic would be noticeably different from those reported in the literature as exhibited by English speakers who possess an individualistic orientation, and also from Arabic-English bilingual speakers given instructions and scales in English. Furthermore, if indeed shame is a more familiar emotion in a collectivistic culture than in an individualistic culture, and language use entails the activation of its corresponding cultural orientation, shame would be more dominant than guilt when Arabic is the language in use. Second, if sequential bilingualism shapes emotional experiences, as suggested by the existing literature, ratings of self-conscious emotions would be more intense when the language that conveys instructions and scales is Arabic (main effect of language).

\section{Method}

\section{Participants}

The participants were 182 female college students, ranging in age from 18 to 25 years old, from Prince Mohammad bin Fahd University (PMU), a private university in the Eastern Region of Saudi Arabia. They reported Arabic as their first language and English as their second language. Students met the university's admission standards by demonstrating English language proficiency through standardized English proficiency tests (i.e., IELTS, Aptis, or TOEFL). According to students' reports, although English had been acquired through formal (86\%) and/or informal instruction (64\%), exposure to English had been more limited in range and scope, and thus more dependent on formal school settings. Arabic was described as the language spoken at home and in all informal settings outside the home. Students' mean English vocabulary score (Shipley, 1940) was $75.75 \%(S E M=1.47)$ and mean reported age of acquisition was 6.74 years $(S E M=.25)$. Furthermore, although students admitted that traditional Arab values and norms were emphasized in their socialization practices, they acknowledged their familiarity with Western modes of living and values transmitted through foreign television channels, the internet, schooling, trips 
abroad, and frequent contacts with the expatriate communities living in Saudi Arabia (see Ménoret, 2005; Murphy, 2012).

\section{Materials and Procedures}

Participants were randomly assigned to one of the four conditions of the experiment created by the combination of emotional scenario (guilt versus shame) and language (Arabic versus English). Participants completed a booklet, which contained instructions and instruments, in either Arabic $(n=109)$ or English $(n=73)$. First, participants were asked to complete the Twenty Statements Test (TST) developed by Kuhn and McPartland (1954). The TST displayed 20 numbered blanks in which each participant was asked to write 20 different answers to the question, "Who Am I?". The TST was used not only to focus participants' attention on the self (Cousins, 1989; Gardner, Gabriel, \& Lee, 1999) at the start of the experiment, but also as a manipulation check, to assess if the dominant orientation (independent versus interdependent) of the self was indeed evoked by the language manipulation.

Adhering to protocols used by Tangney and colleagues (1996) and Shaver, Schwartz, Kirson, and O'Connor (1987), participants were then asked to retrieve events in their personal lives in which they experienced either guilt $(n$ $=94)$ or shame $(n=88)$. To help them retrieve rich and vivid memories of the event, and to become emotionally immersed, prompts were given, including "Think about the details of what you did. What happened to cause you to feel guilt/shame? Why did it happen? What were you thinking and feeling before and after? What physiological signs of guilt/shame did you experience?" (Tangney et al., 1996, p.1259). Instead of the memory work being written as prescribed by Tangney and colleagues, this study's participants were instructed to keep in mind their recollections without producing any written narratives. This procedural change was introduced to ensure privacy.

After recalling the event, each participant completed two scales customarily used to gather information about affective patterns, including the Descriptive Attribute (DA) scale (Wicker et al., 1983), and the Differential Emotion (DE) scale (Mosher \& White, 1981).

This method relies on the assumption that though participants may not be able to define emotions explicitly in terms of their defining attributes, they can nevertheless rate representative exemplars of each emotion that have practical significance to them, one attribute at a time (Izard, 2013).

The DA scale served to obtain an accurate description of the experience induced by the participant's recall. It asked the participant to rate the experience on 34 descriptive dimensions. Dimensions were previously used by Wicker and colleagues (1983), Tangney (1993), and Tangney and colleagues (1996) to differentiate between guilt and shame (see Table 1). They included statements 
regarding (a) the intensity, duration, and onset of the emotion, sensations, and feelings experienced, (b) the evaluation of the responses produced by the participant and others, and (c) the current effect of the recalled experience. Each dimension was defined by two contrasting statements (e.g., "The emotion began gradually" versus "The emotion began suddenly"). Instead of using a scale anchored by contrasting expressions, which participants in a pilot study found confusing, participants rated each contrasting expression on a 5-point scale from 1 (Strongly Disagree) to 5 (Strongly Agree), producing 68 ratings. Contrasting statements, organized in two separate sets, were then randomly ordered for presentation.

To determine the broad affective profile of the recalled experiences, thereby capturing its richness, participants were asked to complete the 5-point DE scale. The use of the scale in the present experiment underscored that emotions in one's personal experience might entail a dominant feeling colored by an array of other feelings. The scale included 12 clusters of adjectives that served to define the phenomenological experience of different fundamental emotions (i.e., shame, guilt, embarrassment, joy, surprise, shyness, sadness, fear, anger, contempt, disgust, and interest). Thus, three adjectives per emotion (e.g., ashamed, humiliated, and disgraced) served as prompts to measure the extent to which the emotion was estimated to apply to the recalled experience.

A randomly selected subset of participants $(n=111)$ then completed the New General Self-Efficacy (NGSE) scale (Chen, Gully, \& Eden, 2001). Because of evidence suggesting that the NGSE scale is sensitive to language changes (Arabic versus English), the scale was used as to assess whether the impact of language on participants' self-orientation encompassed the administration of the two scales used to gather information about affective patterns. Important to note here is that the use of the NGSE scale was based on evidence from two sources. One indicated that transitory affective states (such as those produced by recollecting experiences of self-conscious emotions) are unlikely to affect reports of a stable motivational trait, such as general self-efficacy, which emerges over a person's lifetime as an aggregate of the successes and failures experienced across situations, domains, and activities (see Bandura, 1997; Eden, 1988). The other (El Alaoui et al., 2017) indicated that self-orientation (interdependent versus independent) induced by the language in use may affect such reports. Participants' use of Arabic rather than English can prompt lower estimates of self-efficacy. Thus, if language served as an effective prime for frame switching of self-orientation, an effect of language, but not of an emotional scenario was expected on self-efficacy estimates.

Lastly, all participants completed an English vocabulary test (Shipley, 1940), which was intended to assess their knowledge of the English language. They also responded to a few questions concerning demographic characteristics as well as the time and mode of second-language acquisition. Except for the 
latter (i.e., vocabulary test and demographics/acquisition questions), all scales and instructions had been translated from English to Arabic by three translators whose independent contribution had been sought to ensure the accuracy and naturalness of the Arabic translation. A consensus model was adopted to achieve the goal of a culturally sensitive adaptation of all scales rather than a mere translation (Panayiotou, 2006; Scholz, Doña, Sud, \& Schwarzer, 2002).

\section{Results}

\section{Who am I?}

In the experiment, the TST was used not only to focus participants' attention on their selves at the start of the study, but also to assess whether the participants' dominant self-orientation was consistent with the language condition to which they had been assigned. Thus, responses were scored into one of two categories (Ashton-James, Maddux, Galinsky, \& Chartrand, 2009; Gardner et al., 1999): (a) responses reflecting an interdependent self-construal, including references to group membership, relationships, and social roles (e.g., "I am Saudi", "I am a sister", and "I am a daughter"), or (b) an independent self-construal, including references to personal characteristics that underscore one's distinctiveness (e.g., "I am determined", and "I am sincere"). Responses that were neither independent nor interdependent and reflected physiological or physical attributes and estimates (e.g., "I am hungry", "I am brown-skinned" and "I am 20 years old") were excluded. Five participants, who claimed they were unable to verbalize who they were, chose not to respond to any of the questions. Percentages in each category were submitted to a one-way ANOVA with language (Arabic versus English) as the factor. Because the administration of the TST preceded the instructions to recall an event where participants experienced either guilt or shame, testing of differences in emotional scenario was not performed.

Although a large percentage of responses included personal characteristics, responses were found to be affected by the language in which the question "Who am I?" was asked. Simply stated, English responses $(M=66.36 \%$, $S E M=3.51)$ were more likely than Arabic $(M=49.10 \%, S E M=3.12)$ to yield references to personal characteristics, $F(1,175)=13.51, M S E=962.269, p=$ .001 , Partial ETA ${ }^{2}=.072$. Responses in Arabic $(M=34.04 \%$, SEM $=2.53)$ were more likely than English $(M=23.89 \%, S E M=2.85)$ to yield references to social characteristics, $F(1,175)=13.51, M S E=962.269, p=.001$, Partial ETA $^{2}=.072$. During the debriefing, inquiries indicated that the dominant self-orientation of the five participants who did not respond to the TST was consistent with the language conditions to which they had been assigned. Thus, the data of these participants were included in the analyses described below. 


\section{Descriptions of Shame and Guilt}

It is important to note that no participant reported that she could not recall a real experience of either guilt or shame. A few participants spontaneously wrote comments describing the experience that they were asked to recall. Comments reported next to the TST page were not examined to respect the promise of privacy made to participants at the start of the experiment.

Table 1 displays participants' ratings of DA attributes/expressions that were used to attempt to capture their experience of the recalled event. Ratings on the contrasting expressions of each dimension were reverse scored to compute an average score. Scores were then submitted to a two-way ANOVA with emotional scenario (guilt versus shame) and language (Arabic versus English) as factors. Guilt differed from shame on several dimensions; specifically, the shame scenario yielded more intense reports of being self-conscious and exposed, $F(1,178)=9.80, M S E=.919, p=.002$, Partial $E T A^{2}=.052$, having less control over the situation that induced the emotion, $F(1,178)=4.17, M S E=$ $.787, p=.043$, Partial ETA ${ }^{2}=.023$, being unhappier with oneself, $F(1,178)=$ $4.53, M S E=.492, p=.035$, Partial $E T A^{2}=.025$, and being more likely to expect punishment, $F(1,178)=8.83, M S E=.493, p=.003$, Partial ETA ${ }^{2}=.047$, than the guilt scenario. Furthermore, the shame scenario yielded reports of lower self-confidence, $F(1,178)=6.39, M S E=.857, p=.012$, Partial ETA ${ }^{2}=.035$, and professed dominance, $F(1,178)=6.26, M S E=.412, p=.013$, ${\text { Partial } E T A^{2}}^{2}$ $=.034$, than the guilt scenario. Shame was also perceived as more likely to be caused by one's imagination than guilt, $F(1,178)=4.31, M S E=.500, p=.039$, Partial ETA ${ }^{2}=.024$.

A main effect of language was evident in several expressions; specifically, Arabic-language instruments yielded greater emotional responses to statements reflecting inferiority, $F(1,178)=9.91, M S E=.640, p=.002$, Partial $E T A^{2}=.053$, and ridicule, $F(1,178)=6.10, M S E=.780, p=.014$, Partial $E T A^{2}=.033$ (i.e., "In comparison to others I felt inferior" and "I thought others would laugh a great deal"). In contrast, English-language instruments demonstrated a greater emotional response to statements reflecting internal dimensions, which included unhappiness with one's self, $F(1,178)=15.86$, $M S E=.492, p<.001$, Partial ETA ${ }^{2}=.082$, lack of inhibition, $F(1,178)=$ $6.24, M S E=.735, p=.013$, Partial ETA ${ }^{2}=.034$, and the recognition that the experience recalled might have been shaped by one's thoughts rather than reality, $F(1,178)=8.88, M S E=.500, p=.003$, Partial ETA ${ }^{2}=.047$, (i.e., "I was unhappy with myself in general", "I felt not inhibited", and "The emotion was caused more by my imagination"). In addition, participants given the scale in English were more likely to admit that a written description of the event and its determinants would be easy to complete, $F(1,178)=6.32, M S E=.837, p$ $=.013$, Partial ETA ${ }^{2}=.034$. 
An interaction was observed in responses to a statement that acknowledged participants' lack of control when the event recalled was experienced, $F(1,178)=7.22, M S E=.893, p=.008$, Partial ETA ${ }^{2}=.039$ ("I was not in control"). Specifically, admission of greater lack of control was reported in the guilt scenario than in the shame scenario presented in English, $t(71)=2.53, p=.014$, whereas no differences were found in Arabic-language scenarios, $t<1$, ns (all other $F s \leq 3.17$ ).

\section{Affective Profiles of Shame and Guilt}

The scores of the DE scale, utilized to illustrate the affective profile of guilt and shame, were also submitted to a two-way ANOVA with emotional scenario (guilt versus shame) and language (Arabic versus English) as factors (see Table 2). The mean score of each cluster was the dependent variable. No significant main effects of emotional scenario were observed across all 12 clusters of adjectives $(F s \leq 2.48)$. There were, however, main effects of language on selected clusters. Namely, comparing English- and Arabic-language responses, irrespective of recalled scenario, English-language instruments yielded stronger reports of shame, $F(1,178)=9.20, M S E=.799, p=.003$, Partial ETA ${ }^{2}=.049$, sadness, $F(1,178)=7.76, M S E=.978, p=.006$, Partial ETA ${ }^{2}=.042$, contempt, $F(1,178)=8.09, M S E=.553, p=.005$, Partial ETA ${ }^{2}=.043$, and disgust, $F(1$, $178)=4.33, M S E=.771, p=.039$, Partial $E T A^{2}=.024$. Arabic yielded stronger reports of anger, $F(1,178)=6.06, M S E=.651, p=.015$, Partial ETA ${ }^{2}=.033$, and arousal (including interest, alertness, and curiosity), $F(1,178)=15.65, M S E$ $=.447, p<.001$, Partial ETA ${ }^{2}=.081$. The only significant interaction was observed on the reports of sadness, $F(1,178)=4.99, \mathrm{MSE}=.978, p=.027$, Partial $E T A^{2}=.027$. Feelings of sadness were lower following the guilt scenario than the shame scenario when the Arabic-language instrument was used, $t(107)=$ $2.58, p=.011$, whereas no difference between scenarios was observed when the language used was English, $t<1$, ns.

\section{Self-Efficacy Beliefs}

As expected, self-efficacy scores, which were submitted to a two-way ANOVA with emotional scenario and language as factors, yielded a main effect of language, $F(1,107)=243.49, M S E=.363, p<.001$, Partial $E T A^{2}=.695$, but no main effect of scenario or interaction, $F s \leq 1.06$. Arabic produced lower estimates of self-efficacy $(M=1.99$, SEM $=.075)$ than English $(M=3.80$, SEM = .088 ), supporting the expectation that the influence of the language manipulation would persist beyond the phase during which participants focused on the self-conscious emotion they were asked to recall. The lower score induced by Arabic, which replicated earlier findings by our research team (El Alaoui et al., 
Table 1. Descriptive Statistics (Mean and Standard Error of the Mean) of Participants' Ratings of Phenomenological Experiences of Guilt and Shame (DA Scale).

\begin{tabular}{|c|c|c|c|c|c|}
\hline Phenomenological Dimensions & Mean Guilt & SEM & $\begin{array}{l}\text { Mean } \\
\text { Shame }\end{array}$ & SEM & Language \\
\hline \multicolumn{6}{|l|}{ I felt pain (or pleasure) } \\
\hline Arabic & 3.92 & $(.104)$ & 3.86 & $(.109)$ & 3.89 \\
\hline \multirow[t]{2}{*}{ English } & 3.89 & $(.130)$ & 3.61 & $(.131)$ & 3.75 \\
\hline & 3.91 & & 3.74 & & \\
\hline \multicolumn{6}{|c|}{$\begin{array}{l}\text { In comparison to others I felt inferior (or } \\
\text { superior) }\end{array}$} \\
\hline Arabic & 3.39 & $(.016)$ & 3.44 & $(.111)$ & $3.42^{\star \star}$ \\
\hline \multirow[t]{2}{*}{ English } & 3.12 & $(.132)$ & 2.94 & $(.133)$ & 3.03 \\
\hline & 3.26 & & 3.19 & & \\
\hline \multicolumn{6}{|c|}{ The emotion began suddenly (or gradually) } \\
\hline Arabic & 3.36 & $(.093)$ & 3.23 & $(.097)$ & 3.30 \\
\hline \multirow[t]{2}{*}{ English } & 3.11 & $(.115)$ & 3.13 & $(.117)$ & 3.12 \\
\hline & 3.24 & & 3.18 & & \\
\hline \multicolumn{6}{|c|}{$\begin{array}{l}\text { I felt extremely self-confident and capable } \\
\text { (or not at all) }\end{array}$} \\
\hline Arabic & 3.11 & $(.123)$ & 2.64 & $(.128)$ & 2.88 \\
\hline \multirow[t]{2}{*}{ English } & 2.92 & $(.152)$ & 2.68 & $(.154)$ & 2.80 \\
\hline & $3.02 *$ & & 2.66 & & \\
\hline \multicolumn{6}{|l|}{ I felt tense (or relaxed) } \\
\hline Arabic & 3.68 & $(.110)$ & 3.71 & $(.116)$ & 3.70 \\
\hline \multirow[t]{2}{*}{ English } & 3.82 & $(.137)$ & 3.58 & $(.139)$ & 3.70 \\
\hline & 3.75 & & 3.65 & & \\
\hline \multicolumn{6}{|c|}{$\begin{array}{l}\text { My face was not at all hot and flushed (or } \\
\text { extremely) }\end{array}$} \\
\hline Arabic & 2.78 & $(.123)$ & 2.68 & $(.129)$ & 2.73 \\
\hline \multirow[t]{2}{*}{ English } & 2.68 & $(.153)$ & 2.74 & $(.155)$ & 2.71 \\
\hline & 2.73 & & 2.71 & & \\
\hline \multicolumn{6}{|l|}{ I was dominant (or submissive) } \\
\hline Arabic & 3.15 & $(.085)$ & 3.05 & $(.089)$ & 3.10 \\
\hline \multirow[t]{2}{*}{ English } & 3.15 & $(.105)$ & 2.76 & $(.107)$ & 2.96 \\
\hline & $3.15^{\star}$ & & 2.91 & & \\
\hline \multicolumn{6}{|c|}{$\begin{array}{l}\text { The emotion lasted a short time (or a long } \\
\text { time) }\end{array}$} \\
\hline Arabic & 2.57 & $(.129)$ & 2.44 & $(.135)$ & 2.51 \\
\hline \multirow[t]{2}{*}{ English } & 2.81 & $(.160)$ & 2.46 & $(.162)$ & 2.64 \\
\hline & 2.69 & & 2.45 & & \\
\hline \multicolumn{6}{|c|}{$\begin{array}{l}\text { I was more concerned with how others } \\
\text { viewed me (or how I viewed myself) }\end{array}$} \\
\hline Arabic & 2.57 & $(.104)$ & 2.66 & $(.108)$ & 2.62 \\
\hline \multirow[t]{2}{*}{ English } & 2.81 & (.129) & 2.63 & $(.130)$ & 2.72 \\
\hline & 2.69 & & 2.65 & & \\
\hline \multicolumn{6}{|c|}{$\begin{array}{l}\text { I was unhappy with myself in general (or } \\
\text { only with my behavior) }\end{array}$} \\
\hline Arabic & 2.75 & $(.093)$ & 2.95 & $(.097)$ & 2.85 \\
\hline \multirow[t]{2}{*}{ English } & 3.15 & $(.115)$ & 3.40 & $(.117)$ & $3.28^{\star \star}$ \\
\hline & 2.95 & & $3.18^{*}$ & & \\
\hline
\end{tabular}


After this event, I felt not at all depressed (or extremely)

Arabic

English

2.90

2.45

2.68

$\begin{array}{ll}(.125) & 2.63 \\ (.155) & 2.71 \\ & 2.67\end{array}$

(.131)

(.157)

The emotion was caused more by my

imagination (or things that actually

happened)

Arabic

2.24

(.094)

2.54

(.098)

2.39

English

2.64

(.116) 2.78

(.118)

$2.71 * \star$

A short written description of why I felt

2.44

$2.66^{*}$

uncomfortable would be easy to do (or

difficult)

Arabic

2.48

(.121) 2.39

(.127)

2.44

English

2.88

(.150)

2.69

(.152)

$2.79 * \star$

I felt my status in the situation was too low

2.68

2.54

(or too high)

Arabic

3.23

(.107)

3.22

(.112)

3.23

English

3.15

(.132)

3.01

(.134)

3.08

My actions were inappropriate to the

3.19

3.12

situation (or appropriate)

Arabic

English

3.18

3.27

(.115) $\quad 3.26$

(.121) $\quad 3.22$

3.23

(.143) 2.97

(.145) 3.12

In this situation, my attention was scat-

3.12

tered and distracted (or focused and

concentrated)

Arabic

3.09

English

3.24

3.17

(.115) 2.90

(.120)

3.00

(.143) $\quad 3.00$

(.145)

3.12

I was feeling cooperative (or competitive)

Arabic

3.02

2.95

English

2.99

(.099) $\quad 2.90$

(.103)

2.96

(.122) $\quad 3.01$

(.124) 2.98

I thought I would be punished (or aban-

doned)

Arabic

3.02

$\begin{array}{ll}(.093) & 3.14 \\ (.115) & 3.17\end{array}$

(.097)

3.08

English

2.66

2.84

$3.16^{\star}$

I wanted to hide (or make restitution)

Arabic

3.12

(.107)

3.14

(.117)

2.92

English

3.04

(.133)

3.24

(.112)

3.13

3.08

3.19

(.135) 3.14

I thought others would laugh a great deal

(or not at all)

Arabic

2.85

(117)

2.89

$(.122)$

(.145)

2.64

(.147)

$2.87^{\star \star *}$

2.45

2.77 
I was not surprised (or surprised)

Arabic

English

I felt extremely self-conscious or

"exposed" (or not at all)

Arabic

English

I felt my power in the situation was too

little (or too much)

Arabic

English

I felt not inhibited (or inhibited)

Arabic

English

I wanted to reward others (or punish oth-

ers)

Arabic

English

I felt strongly I had done an unjust thing

(or not at all)

Arabic

I was concerned with the future (or the present)

Arabic

English

I was active (or passive)

Arabic

English

Negative evaluation was coming more

from myself (or others)

Arabic

English

The situation was uncertain (or clear)

Arabic

English

I felt I was not at all exceeding boundaries of correct behavior (or greatly)

Arabic

English
3.10

2.89

3.00

3.11

3.28

3.20

2.68
2.38

2.53

3.25

3.01

3.13

2.71

2.99

2.85

2.98

2.74

2.86

2.88

3.15

3.02

3.15

3.16

3.16

3.41

3.31

3.36

3.03

3.03

3.03

2.89

3.14

3.02
(.125) 2.56

(.156) 2.68

2.62

(.127) $\quad 3.58$

(.158) $\quad 3.32$

3.45 *

(.133) 3.34

(.160) $\quad 3.11$

$\begin{array}{ll}(.117) & 3.41 \\ (.146) & 3.40 \\ & 3.41^{\star}\end{array}$

(.123) 3.33

(.148) $\quad 3.21$

(.114) 2.59

(.141) $\quad 2.96$

2.78

(.119) 2.65

(.143) 2.98**

(.102) 2.94

(.126) 2.94

2.94

(.107) $\quad 2.96$

(.128) 2.84

(.112) 3.02

$\begin{array}{ll}(.117) & 3.07\end{array}$

(.139) $\quad 3.08$

(.141) $\quad 3.18$

3.05

$\begin{array}{ll}(.105) & 2.98 \\ (.130) & 3.06 \\ & 3.02\end{array}$

(.109)

2.93

(.132) $\quad 3.11$

$\begin{array}{ll}(.110) & 3.02 \\ (.137) & 2.99 \\ & 3.01\end{array}$

(.115) $\quad 3.09$

(.139) $\quad 3.08$

(.102) $\quad 3.30$

(.107) 3.36

(.127) $\quad 3.61$

(.128) $\quad 3.46$

3.46

(.105) $\quad 3.06$

(.110) 3.05

(.131) 2.94

(.132) 2.99

3.00

$\begin{array}{ll}(.102) & 3.04 \\ (.126) & 3.04 \\ & 3.04\end{array}$

(.106) 2.97

(.128) 3.09 


$\begin{array}{llllll}\text { I was not in control (or in control) *** } & & & & & \\ \text { Arabic } & 3.19 & (.125) & 3.33 & (.131) & 3.26 \\ \text { English } & 3.65 & (.155) & 3.01 & (.158) & 3.33 \\ & 3.42 & & 3.17 & & \\ \text { My body felt calm (or agitated and } & & & & & \\ \text { aroused) } & & & & & \\ \text { Arabic } & 2.80 & (.132) & 2.77 & (.138) & 2.79 \\ \text { English } & 2.58 & (.164) & 2.86 & (.166) & 2.72 \\ & 2.69 & & 2.82 & & \\ \text { Others were rejecting me (or accepting me) } & & & & & \\ \text { Arabic } & 2.56 & (.115) & 2.60 & (.121) & 2.58 \\ \text { English } & 2.72 & (.143) & 2.67 & (.145) & 2.70 \\ & 2.64 & & 2.64 & & \end{array}$

${ }^{*} p<.05$. The location of the asterisk indicates greater values for either guilt or shame scenario

${ }^{\star \star} p<.05$. The location of the asterisk indicates greater values for either Arabic or English

$\star * \star p<.05$. Significant interaction

2017), is consistent with the appreciation for modest self-presentation typical of collectivistic cultures (see Kurman, 2001; 2003; Kurman \& Sriram, 2002).

\section{Discussion}

Because emotions guide and motivate cognition and behavior (Baumeister, Reis, \& Delespaul, 1995; Baumeister, Stillwell, \& Heatherton, 1995; LindsayHartz, de Rivera, \& Mascolo, 1995; Tomkins, 1970; Weiner, 1992), they are important aspects of how a culture is expressed and experienced by its members. Within this framework, self-conscious emotions, such as shame and guilt, are reactions to undesirable actions and outcomes that can instinctually underscore the demarcation between a culture's socially desirable and undesirable behaviors. In the present study, we inquired about the defining characteristics of these emotions in young female residents of Saudi Arabia, who could be described as Arabic-English sequential bilingual speakers, and who, as a result of language acquisition processes and acculturation, were thought to have interiorized the dominant cultural orientation evoked by each language. The experimental procedure did not compel participants to compare self-conscious emotions because it was feared that forcing a comparison could lead participants to exaggerate or even imagine differences. Arabic-English bilingual speakers were merely asked to describe either guilt or shame scenarios through both attributes (DA scale) and common emotion adjectives (DE scale).

The findings of the present study can be summarized in two main points based on the scales used: First, DA ratings, obtained from a scale used to gather descriptive information, supported not only the prediction that these emotions are seen as different by Arabic-English bilingual speakers, but also the notion 
Table 2. Descriptive Statistics (Mean and Standard Error of the Mean) of Ratings of Guilt and Shame Experiences on the DE Scale.

\begin{tabular}{|c|c|c|c|c|c|}
\hline Emotional Experience & $\begin{array}{c}\text { Mean } \\
\text { Guilt }\end{array}$ & SEM & $\begin{array}{l}\text { Mean } \\
\text { Shame }\end{array}$ & SEM & Language \\
\hline \multicolumn{6}{|c|}{ Shame: Ashamed, humiliated, \& disgraced } \\
\hline Arabic & 2.64 & $(.118)$ & 2.99 & $(.124)$ & 2.82 \\
\hline \multirow[t]{2}{*}{ English } & 3.24 & $(.147)$ & 3.21 & (.149) & $3.23^{\star}$ \\
\hline & 2.94 & & 3.10 & & \\
\hline \multicolumn{6}{|c|}{ Guilt: Repentant, guilty, \& blameworthy } \\
\hline Arabic & 3.56 & (.119) & 3.63 & $(.125)$ & 3.60 \\
\hline \multirow[t]{2}{*}{ English } & 3.55 & $(.148)$ & 3.19 & $(.150)$ & 3.37 \\
\hline & 3.56 & & 3.41 & & \\
\hline \multicolumn{6}{|c|}{$\begin{array}{l}\text { Embarrassment: Embarrassed, self- } \\
\text { conscious, \& blushing }\end{array}$} \\
\hline Arabic & 3.23 & $(.115)$ & 3.52 & $(.121)$ & 3.38 \\
\hline \multirow[t]{2}{*}{ English } & 3.83 & $(.143)$ & 3.39 & $(.145)$ & 3.61 \\
\hline & 3.53 & & 3.46 & & \\
\hline \multicolumn{6}{|l|}{ Glad, happy, \& joyful } \\
\hline Arabic & 2.34 & $(.147)$ & 2.49 & $(.154)$ & 2.42 \\
\hline \multirow{2}{*}{ English } & 2.22 & $(.183)$ & 2.17 & $(.185)$ & 2.2 \\
\hline & 2.28 & & 2.33 & & \\
\hline \multicolumn{6}{|c|}{ Surprised, amazed, \& astonished } \\
\hline Arabic & 3.37 & (.119) & 3.32 & $(.124)$ & 3.35 \\
\hline \multirow[t]{2}{*}{ English } & 3.29 & $(.147)$ & 3.19 & $(.149)$ & 3.24 \\
\hline & 3.33 & & 3.26 & & \\
\hline \multicolumn{6}{|c|}{ Sheepish, bashful, \& shy } \\
\hline Arabic & 2.99 & $(.096)$ & 3.28 & $(.101)$ & 3.14 \\
\hline \multirow[t]{2}{*}{ English } & 3.22 & (.119) & 3.19 & $(.121)$ & 3.21 \\
\hline & 3.11 & & 3.24 & & \\
\hline \multicolumn{6}{|c|}{ 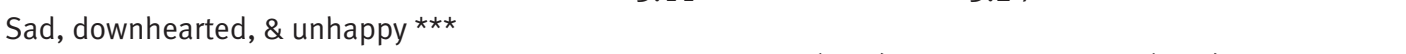 } \\
\hline Arabic & 3.01 & $(.131)$ & 3.52 & (.137) & 3.27 \\
\hline \multirow[t]{2}{*}{ English } & 3.76 & $(.163)$ & 3.60 & $(.165)$ & $3.68^{\star}$ \\
\hline & 3.39 & & 3.56 & & \\
\hline \multicolumn{6}{|l|}{ Scared, fearful, \& afraid } \\
\hline Arabic & 3.08 & $(.114)$ & 3.37 & $(.119)$ & 3.23 \\
\hline \multirow[t]{2}{*}{ English } & 3.41 & $(.141)$ & 3.53 & $(.143)$ & 3.47 \\
\hline & 3.25 & & 3.45 & & \\
\hline \multicolumn{6}{|c|}{ Angry, irritated, \& annoyed } \\
\hline Arabic & 3.91 & $(.107)$ & 3.90 & $(.112)$ & $3.91 *$ \\
\hline \multirow[t]{2}{*}{ English } & 3.70 & $(.133)$ & 3.51 & $(.134)$ & 3.61 \\
\hline & 3.81 & & 3.71 & & \\
\hline \multicolumn{6}{|c|}{ Contemptuous, scornful, \& disdainful } \\
\hline Arabic & 2.61 & $(.099)$ & 2.87 & $(.103)$ & 2.74 \\
\hline \multirow{2}{*}{ English } & 3.07 & $(.122)$ & 3.06 & $(.124)$ & $3.07^{\star}$ \\
\hline & 2.84 & & 2.97 & & \\
\hline \multicolumn{6}{|c|}{ Disgusted, distaste, \& revulsion } \\
\hline Arabic & 3.02 & $(.116)$ & 3.05 & $(.122)$ & 3.04 \\
\hline \multirow[t]{2}{*}{ English } & 3.32 & $(.144)$ & 3.31 & $(.146)$ & $3.32^{\star}$ \\
\hline & 3.17 & & 3.18 & & \\
\hline Interested, alert, \& cur & & & & & \\
\hline Arabic & 3.38 & $(.091)$ & 3.24 & (.096) & $3.31^{\star}$ \\
\hline English & 2.92 & $(.113)$ & 2.88 & $(.115)$ & 2.90 \\
\hline & 3.15 & & 3.06 & & \\
\hline
\end{tabular}

${ }^{\star} p<.05$. The location of the asterisk indicates greater values for either Arabic or English

$\star \star \star ~ p<.05$. Significant interaction 
that shame embodies a number of experiences of a self that painfully recognizes its weaknesses in relation to others (either real or imagined). Namely, experiences of shame were reported to be more related to self-consciousness, powerlessness, unhappiness with oneself, inadequate self-confidence, and fear of punishment than those of guilt. Interestingly, the realization of the role played by one's imagination was more likely to be associated with shame than guilt, thereby reinforcing the impression that an interiorized audience, rather than a real one, is largely responsible for the feelings of shame. However, when lack of control was felt, it was reported to be more intense for guilt than shame experienced in English, whereas there were no differences in Arabic. Additionally, language mattered, but in a way contrary to the hypothesis of higher emotionality for the first language. Language differences mostly underlined differences in participants' focus of attention, either others or oneself. Namely, for both emotions, Arabic fostered attention to others, such as a feeling of inferiority and fear of ridicule, whereas English fostered attention to oneself, such as unhappiness with oneself and awareness of the role of one's imagination in the experience of self-conscious emotions. Participants were also more amenable to provide a written description of the situation where they experienced such emotions in English than in Arabic, perhaps as a way of distancing themselves from an unpleasant experience (as reported informally by some participants at the end of the experiment). The latter finding is consistent with the notion that the second language is more likely to reflect the speaker's emotional control and distance (Bond \& Lai, 1986; Dewaele \& Pavlenko, 2002; Ervin, 1964).

Second, if differences between guilt and shame were reported on attributes intended to represent descriptive, situational aspects of either emotion, the adjectives of the DE scale were unable to confirm them. The adjectives served as prompts to measure the likely complexities of a real event in which participants might have experienced a self-conscious emotion along with other feelings. Previous research showed the scale as capable of differentiating between guilt and shame if administered to English-speakers who subscribe to an individualistic cultural orientation (e.g., Americans; Mosher \& White, 1981). Our participants did not replicate this finding. Spontaneous comments made at the end of the experiment indicated that the adjectives of the DE scale were perceived as too abstract and general to fit the concrete events that our participants recalled.

DE ratings did not support the hypothesis that Arabic-English bilingual speakers would differentiate between shame and guilt, and did not support the hypothesis that Arabic, the first language of our participants, would trigger more intense emotional experiences than English, their second language. In fact, irrespective of the recalled scenario, English induced stronger expressions of shame, sadness, contempt, and disgust. The exception was Arabic inducing stronger expressions of anger and arousal (including interest, curiosity, and alertness). In one isolated instance, when emotional scenario also mattered, 
findings illustrated elevated sadness for both guilt and shame recalled in English. In Arabic, participants expressed less sadness when guilt instead of shame was experienced, distinguishing between the two scenarios.

Although a descriptive scale with concrete attributes (DA) was more sensitive than a scale of adjectives (DE) to the content of participants' recollections, important to note is that only a few attributes/expressions were able to differentiate between shame and guilt. The English-speaking, individualistically oriented participants of the study of Wicker and colleagues (1983), for instance, found a greater number of attributes that could distinguish these emotions. In most cases, however, our participants made differentiations mostly in the same direction. A notable exception was the expectation of punishment (i.e., "I thought I would be punished") which our participants rated as greater for shame, whereas the participants of the Wicker study rated as greater for guilt. Interestingly, a critical dimension of Lewis's (1971) definition of these selfconscious emotions, which is the person's focus on one's self versus one's behavior (i.e., "I was unhappy with myself in general" versus "I was unhappy only with my behavior"), was captured by the DA measure. Shame scenario yielded a greater focus on oneself. The responses to this critical dimension produced by the English-speaking, individualistically oriented participants of Tangney and colleagues (1996) and those of Wicker and colleagues (1983) did not differentiate between guilt and shame scenarios. Furthermore, whenever our participants' responses differentiated between these two emotions, they did so in both languages. The influence of language was mostly visible in participants' self-orientation, in the form of either an interdependent or an independent self, suggesting that Arabic and English can direct attention to cultural constructs that evoke a communal and a solipsistic orientation, respectively. However, such orientations do not share profoundly different conceptualizations of guilt and shame that could be captured by our scales.

\section{Conclusions}

Although conclusive answers on the affective patterns of shame and guilt in Saudi nationals would require a larger and more diverse sample, one encompassing different age groups, genders, and socioeconomic backgrounds, the evidence collected in the present study opens a window into the minds of Arabic-English sequential speakers and their affective experiences. In doing so, it dispels the notion that collectivistic and individualistic orientations yield profoundly different experiences of self-conscious emotions. The relative dominance of shame (as evidenced by DA ratings) speaks of a more insidious influence of a vertical collectivistic culture whereby themes of powerlessness, punishment, and exposure of one's faults and weakness to others are recurrent events in a person's daily life (Omar, 2014). 
Interestingly, the present study brings to the forefront the question of whether diverse collectivistic cultures, such as those of many Asian and Middle Eastern cultures, can be treated as monolithic entities whose members experience self-conscious emotions similarly. The salience and commonality of shame among inhabitants of nations of east Asia (see Wong \& Tsai, 2007) as well as of nations of the Arab League (see Bierbrauer, 1992; Feghali, 1997) have been previously documented. Differences yet to be unearthed may exist; consider, for instance, the findings that shame is viewed as a more appropriate response than anger by Chinese youth (Cole, Bruschi, \& Tamang, 2002), which is consistent with the Confucian roots of Chinese parenting practices focused on restraining emotional expression (Bond \& Hwang, 1986). Evidence exists that Saudi nationals experience disengaging emotions (e.g., anger) at levels similar to those reported by Americans (Maddux et al., 2011). Moreover, both groups report higher levels than those experienced by Japanese nationals (Maddux et al., 2011), suggesting variability in either communication practices of affective events or in the actual phenomenology of such events within a single macroscopic cultural orientation.

Another question that this study brings to the forefront is the extent to which demographic differences within Saudi society are accompanied by differences in the experience of self-conscious emotions. In our study, female college students were selected to fill a gap in the non-clinical literature about their experiences of self-conscious emotions. The unique status of young women within Saudi society placed our participants at the center of a struggle between conflicting cultural frames, simplistically rendering them symbols of either change or tradition (Ménoret, 2005). As such, they were the ideal candidates for a study where language was used to activate conflicting cultural frames in order to observe their effects on reports of self-conscious emotions. Yet, a sample of young women, all college students, also limited the generalizability of our results. Thus, one may ask whether other demographic groups, such as young men, older women and men, and individuals of different socioeconomic backgrounds, who are not so much at the center of opposing cultural forces, would respond similarly to measures of self-conscious emotions. Although only future research can directly answer this question, at the present time, we can speculate that the answer will depend on the content of the cultural frames such individuals possess. According to Hong and colleagues (2000), cultural frames, known as interiorized cultures, are meaning systems consisting of loose networks of constructs, which have the ability to control cognition, affect, and behavior when they are active in people's mind. Although several dimensions may be used to define cultural frames in order to capture the complexities of cultures around the world (see Hofstede, 2001; Hofstede \& Hofstede, 2005), in our current and earlier studies, including related pilot work, we found one's self-orientation (i.e., the independent self as advocated by individualism versus 
the interdependent self as advocated by collectivism) to be the most useful. Perhaps the reason is that this dimension most candidly captures the economic concerns currently faced by people in Saudi Arabia, which involve the excesses of consumerism, diminishing natural resources, and the sustainability of the subsidized welfare state (Assad, 2006). Future research will have to examine whether other dimensions may be equally useful to define the cultural frames possessed by the multitude of individuals who call Saudi Arabia home.

Lastly, it is important to recognize that because cross-cultural studies have used a variety of measurement instruments and cross-group comparisons, it is difficult to determine the extent to which differences in the responses of members of disparate national groups illustrate true differences in affective profiles, including modes of experience and expression, or are merely the effect of methodological differences. Of course, in the age of globalization, diverse cultural orientations may become progressively less diverse. Abdullah Al-Ghadhami, a keen cultural critic, has observed that young people in Saudi Arabia are progressively embracing independence and individualism (2013), implying that in the struggle to integrate collectivism and individualism, the latter is winning. Bilingual speakers, who embody more than one cultural orientation, will continue to be the ideal thermometer for measuring the extent to which diversity can indeed resist globalization.

\section{References}

Al-Ghadhami, A. (2013). The hand and the tongue. Literacy, illiteracy, and the capitalistic culture. Casablanca, Morocco: Arab Cultural Center. [in Arabic]

Al-Ghadhami, A. (2014). The story of modernity in the Kingdom of Saudi Arabia. Casablanca, Morocco: Arab Cultural Center. [in Arabic]

Anooshian, J. L., \& Hertel, T. P. (1994). Emotionality in free recall: Language specificity in bilingual memory. Cognition and Emotion, 8, 503-514. https://doi. org/10.1080/02699939408408956

Ashton-James, C. E., Maddux, W. W., Galinsky, A. D., \& Chartrand, T. L. (2009). Who I am depends on how I feel: The role of affect in the expression of culture. Psychological Science, 20(3), 340-346. https://doi.org/10.1111/j.1467-9280.2009.02299.x

Assad, S. W. (2006). Facing the challenges of consumerism in Saudi Arabia. Arts, 19(1), $1-20$.

Ausubel, D. P. (1955). Relationships between shame and guilt in the socializing process. Psychological Review, 62(5), 378-390. https://doi.org/10.1037/h0042534

Bandura, A. (1997). Self-efficacy: The exercise of control. New York: Freeman \& Company.

Baumeister, R. F., Reis, H. T., \& Delespaul, P. A. (1995). Subjective and experiential correlates of guilt in daily life. Personality and Social Psychology Bulletin, 21(12), 1256-1268. https://doi.org/10.1177/01461672952112002

Baumeister, R. F., Stillwell, A. M., \& Heatherton, T. F. (1995). Personal narratives about guilt: Role in action control and interpersonal relationships. Basic and Applied Social Psychology, 17(1-2), 173-198. https://doi.org/10.1080/01973533.1995.9646138 
Bierbrauer, G. (1992). Reactions to violation of normative standards: A cross-cultural analysis of shame and guilt. International Journal of Psychology, 27(2), 181-193. https://doi.org/10.1080/00207599208246874

Bond, M. H., \& Hwang, K. K. (1986). The social psychology of Chinese people. Oxford, UK: Oxford University Press.

Bond, M. H., \& Lai, T. (1986). Embarrassment and code-switching into a second language. Journal of Social Psychology, 126, 179-186.

Campos, J. J., \& Barrett, K. C. (1984). Toward a new understanding of emotions and their development. In C. Izard, J. Kagan, \& R. Zajonc (Eds.), Emotions, cognition, and behavior (pp. 229-263). Cambridge, UK: Cambridge University Press.

Chen, G., Gully, S. M., \& Eden, D. (2001). Validation of a new general selfefficacy scale. Organizational Research Methods, 4(1), 62-83. https://doi. org/10.1177/109442810141004

Cole, P. M., Bruschi, C. J., \& Tamang, B. L. (2002). Cultural differences in children's emotional reactions to difficult situations. Child Development, 73, 983-996. https:// doi.org/10.1111/1467-8624.00451

Cousins, S. D. (1989). Culture and self-perception in Japan and the United States. Journal of Personality and Social Psychology, 56(1), 124-131. https://doi.org/10.1037/00223514.56.1.124

Dewaele, J. M., \& Pavlenko, A. (2002). Emotional vocabulary in interlanguage. Language Learning, 52, 263-322. https://doi.org/10.1111/0023-8333.00185

Dwairy, M., Achoui, M., Abouserie, R., \& Farah, A. (2006). Adolescent-family connectedness among Arabs a second cross-regional research study. Journal of CrossCultural Psychology, 37, 248-261. https://doi.org/10.1177/0022022106286923

Eden, D. (1988). Pygmalion, goal setting, and expectancy: Compatible ways to raise productivity. Academy of Management Review, 13, 639-652.

El Alaoui, K., Mulhem, H., Pilotti, M. A. E., \& al-Mqbas M. M. A. (2017). Priming of self-assessment: Do words speak louder than images? Journal of Global Research in Education and Social Science, 10(3), 101-111.

El Alaoui, K., Mulhem, H., Pilotti, M. A. E., Amir, S., \& Tallouzi, E. (2017). ArabicEnglish bilingual speakers' reactions to the statements of the new general selfefficacy scale. The International Journal of Learner Diversity and Identities, 24(2), 21-38. https://doi.org/10.18848/2327-0128/CGP/v24i02/21-38

Ervin, S. M. (1964). Language and TAT content in bilinguals. Journal of Abnormal and Social Psychology, 5, 500-507. https://doi.org/10.1037/h0044803

Feghali, E. (1997). Arab cultural communication patterns. International Journal of Intercultural Relations, 21, 345-378. https://doi.org/10.1016/S01471767(97)00005-9

Fessler, D. M. T. (2004). Shame in two cultures: Implications for evolutionary approaches. Journal of Cognition and Culture, 4, 207-262. https://doi. org/10.1163/1568537041725097

Gardner, W.L., Gabriel, S., \& Lee, A. Y. (1999). "I" value freedom, but "we" value relationships: Self-construal priming mirrors cultural differences in judgment. Psychological Science, 10, 324-330. https://doi.org/10.1111/1467-9280.00162

Ghorbani, M., \& Liao, Y. (2014). The Effect of Acculturation on Reparative Behavior in Shame and Guilt Cultures. Frontiers of Business Research in China, 8(3), 273-298.

Gilbert, P. (2003). Evolution, social roles, and the differences in shame and guilt. Social Research, 70, 1205-1230.

Hall, E. T. (1966). The hidden dimension. New York, NY: Doubleday.

Harris, C. L., Aycicegi, A., \& Gleason, J. B. (2003). Taboo words and reprimands elicit 
greater autonomic reactivity in a first language than in a second language. Applied Psycholinguistics, 24, 561-579. https://doi.org/10.1017/S0142716403000286

Ho, D.Y. F., Fu, W., \& Ng, S. M. (2004). Guilt, shame and embarrassment: revelations of face and self. Culture \& Psychology, 10, 64-84. https://doi. org/10.1177/1354067X04044166

Hoffman, C., Lau, I., \& Johnson, D. R. (1986). The linguistic relativity of person cognition: An

English-Chinese comparison. Journal of Personality and Social Psychology, 51, 10971105. https://doi.org/10.1037/0022-3514.51.6.1097

Hofstede, G. (2001). Culture's consequences: Comparing values, behaviors, institutions and organizations across nations. Thousand Oaks, CA: Sage.

Hofstede, G., \& Hofstede, G. J. (2005). Cultures and organizations: Software of the mind. New York: McGraw-Hill.

Hong, Y. Y., Morris, M. W., Chiu, C. Y., \& Benet-Martinez, V. (2000). Multicultural minds: A dynamic constructivist approach to culture and cognition. American Psychologist, 55, 709-720. https://doi.org/10.1037/0003-066X.55.7.709

Izard, C. E. (2013). Human emotions. New York: Springer.

Johnson, R. C., Danko, G. P., Huang, Y. H., Park, J. Y., Johnson, S. B., \& Nagoshi, C. T. (1987). Guilt, shame, and adjustment in three cultures. Personality and Individual Differences, 8, 357-364. https://doi.org/10.1016/0191-8869(87)90036-5

Kim, Y. Y. (1988). Communication and cross-cultural adaptation: An integrative theory. Philadelphia, PA: Multilingual Matters.

Kitayama, S., \& Markus, H. (1995). Construal of the self as a cultural frame: Implications for internationalizing psychology. In N. R. Goldberger \& J. B. Veroff (Eds.), The culture and psychology reader (pp. 366-383). New York: New York University Press.

Kitayama, S., Markus, H. R., \& Kurokawa, M. (2000). Culture, emotion, and well-being: Good feelings in Japan and the United States. Cognition \& Emotion, 14(1), 93-124. https://doi.org/10.1080/026999300379003

Kitayama, S., Markus, H. R., \& Matsumoto, H. (1995). Culture, self, and emotion: A cultural perspective on" self-conscious" emotions. In J. Tangney \& K. Fischer (Eds.), Self-conscious emotions: The psychology of shame, guilt, embarrassment, and pride (pp. 339-364). New York: Guilford.

Kitayama, S., Mesquita, B., \& Karasawa, M. (2006). Cultural affordances and emotional experience: socially engaging and disengaging emotions in Japan and the United States. Journal of Personality and Social Psychology, 91(5), 890-903. https://doi. org/10.1037/0022-3514.91.5.890

Kuhn, M. H., \& McPartland, T. S. (1954). An empirical investigation of self-attitudes. American Sociological Review, 19, 68-76. https://doi.org/10.2307/2088175

Kurman, J. (2001). Self-enhancement: Is it restricted to individualistic cultures? Personality and Social Psychology Bulletin, 27, 1705-1716. https://doi. org/10.1177/01461672012712013

Kurman, J. (2003). Why is self-enhancement low in certain collectivist cultures? An investigation of two competing explanations. Journal of Cross-Cultural Psychology, 34, 496-510. https://doi.org/10.1177/0022022103256474

Kurman, J., \& Sriram, N. (2002). Interrelationships among vertical and horizontal collectivism, modesty, and self-enhancement. Journal of Cross-Cultural Psychology, 33, 71-86. https://doi.org/10.1177/0022022102033001005

LaFromboise, T., Coleman, H. L., \& Gerton, J. (1993). Psychological impact of bicul- 
turalism: Evidence and theory. Psychological Bulletin, 114, 395-412. https://doi. org/10.1037/0033-2909.114.3.395

Lewis, H. B. (1971). Shame and guilt in neurosis. New York: International Universities Press.

Li, J., Wang, L., \& Fischer, K.W. (2004). The organization of Chinese shame concepts. Cognition and Emotion, 18, 767-797. https://doi.org/10.1080/02699930341000202

Lindsay-Hartz, J., De Rivera, J., \& Mascolo, M. F. (1995). Differentiating guilt and shame and their effects on motivation. In J. Tangney \& K. Fischer (Eds.), Selfconscious emotions: The psychology of shame, guilt, embarrassment, and pride (pp. 274-300). New York: Guilford.

Maddux, W. W., San Martin, A., Sinaceur, M., \& Kitayama, S. (2011, July). In the middle between East and West: Implicit cultural orientations in Saudi Arabia. Paper presented at the $24^{\text {th }}$ Annual International Association of Conflict Management Conference, Istanbul.

Markus, H., \& Kitayama, S. (1991). Culture and self: Implication for cognition, emotion, and motivation. Psychological Review, 98, 224-253. https://doi.org/10.1037/0033295X.98.2.224

Marsella, A. J., Murray, M. D., \& Golden, C. (1974). Ethnic Variations in the Phenomenology of Emotions I. Shame. Journal of Cross-Cultural Psychology, 5, 312-328. https://doi.org/10.1177/002202217400500305

Ménoret, P. (2005). The Saudi enigma: A history. London: Zed Books.

Mosher, D. L., \& White, B. B. (1981). On differentiating shame and shyness. Motivation and Emotion, 5, 61-74. https://doi.org/10.1007/BF00993662

Murphy, C. (2012). A Kingdom's future: Saudi Arabia through the eyes of its twentysomethings. Washington, DC: Woodrow Wilson International Center for Scholars, Middle East Program.

Nelissen, R., Breugelmans, S. M., \& Zeelenberg, M. (2013). Reappraising the moral nature of emotions in decision making: The case of shame and guilt. Social and Personality Psychology Compass, 7, 355-365. https://doi.org/10.1111/spc3.12030

Omar, G. H. (2014). What happened to the Saudis? Riyadh: Dar al-Manahel. [in Arabic]

Opitz, B., \& Degner, J. (2012). Emotionality in a second language: It's a matter of time. Neuropsychologia, 50, 1961-1967. https://doi.org/10.1016/j.neuropsychologia.2012.04.021

Panayiotou, A. (2006). Translating guilt: An endeavor of shame in the Mediterranean? In A. Pavlenko (Ed.), Bilingual minds: Emotional experience, expression, and representation (Vol. 56, pp. 183-207). Clevedon, UK: Multilingual Matters.

Pavlenko, A. (2008). Emotion and emotion-laden words in the bilingual lexicon. Bilingualism: Language and Cognition, 11, 147-164. https://doi.org/10.1017/ S1366728908003283

Scheff, T. J. (1994). Microsociology: Discourse, emotion, and social structure. Chicago: University of Chicago Press.

Scholz, U., Doña, B. G., Sud, S., \& Schwarzer, R. (2002). Is general self-efficacy a universal construct? Psychometric findings from 25 countries. European Journal of Psychological Assessment, 18, 242-251. https://doi.org/10.1027//1015-5759.18.3.242

Schrauf, R. W. (2000). Bilingual autobiographical memory: Experimental studies and clinical cases. Culture and Psychology, 6, 387-417. 10.1177/1354067X0064001

Sharabi, H. (1977). Impact of class and culture on social behavior: The feudal bourgeois family in Arab society. In L. C. Brown \& N. Itzhowitz (Eds.), Psychological dimensions of Near Eastern studies (pp. 24\&256). Princeton, NJ: Darwin Press. 
Shaver, P., Schwartz, J., Kirson, D., \& O’Connor, C. (1987). Emotional knowledge: Further exploration of a prototype approach. Journal of Personality and Social Psychology, 52, 1061-1086. https://doi.org/10.1037/0022-3514.52.6.1061

Shipley, W. C. (1940). A self-administering scale for measuring intellectual impairment and deterioration. Journal of Psychology, 9, 371-377. https://doi.org/10.1080/0022 3980.1940.9917704

Singelis, T. M., Triandis, H. C., Bhawuk, D. P. S., \& Gelfand, M. J. (1995). Horizontal and vertical dimensions of individualism and collectivism: a theoretical and measurement refinement. Cross-Cultural Research, 29, 240-275. https://doi. org/10.1177/106939719502900302

Smith, C. A., \& Ellsworth, P. C. (1985). Patterns of cognitive appraisal in emotion. Journal of Personality and Social Psychology, 48, 813-838. https://doi.org/10.1037/00223514.48.4.813

Smith, C. A., \& Ellsworth, P. C. (1987). Patterns of appraisal and emotion related to taking an exam. Journal of Personality and Social Psychology, 52, 475-488. https:// doi.org/10.1037/0022-3514.52.3.475

Souryal, S. S. (1987). The religionization of a society: The continuing application of Shariah law in Saudi Arabia. Journal for the Scientific Study of Religion, 26, 429449. https://doi.org/10.2307/1387096

Stipek, D. (1998). Differences between Americans and Chinese in the circumstances evoking pride, shame, and guilt. Journal of Cross-Cultural Psychology, 29, 616-629. https://doi.org/10.1177/0022022198295002

Tangney, J. P. (1992). Situational determinants of shame and guilt in young adulthood. Personality and Social Psychology Bulletin, 18, 199-206. https://doi. org/10.1177/0146167292182011

Tangney, J. P. (1993). Shame and guilt. In C. G. Costello (Ed.), Symptoms of depression (pp. 161-180). New York: Wiley.

Tangney, J. P., Burggraf, S. A., \& Wagner, P. E. (1995). Shame-proneness, guiltproneness, and psychological symptoms. In J. Tangney \& K. Fischer (Eds.), Selfconscious emotions: The psychology of shame, guilt, embarrassment, and pride (pp. 343-367). New York: Guilford.

Tangney, J. P., Miller, R. S., Flicker, L., \& Barlow, D. H. (1996). Are shame, guilt, and embarrassment distinct emotions? Journal of Personality and Social Psychology, 70, 1256-1269. https://doi.org/10.1037/0022-3514.70.6.1256

Tomkins, S. S. (1970). Affects as primary motivational system. In M. Arnold (Ed.), Feelings and emotions (pp. 101-110). New York: Academic Press. https://doi. org/10.1016/B978-0-12-063550-4.50013-9

Trafimow, D., Silverman, E. S., Fan, R. M. T., \& Fun Law, J. S. (1997). The effects of language and priming on the relative accessibility of the private self and the collective self. Journal of Cross-Cultural Psychology, 28, 107-123. https://doi. org//10.1177/0022022197281007

Triandis, H. C. (1989). The self and social behavior in differing cultural contexts. Psychological Review, 96, 506-520. https://doi.org/10.1037/0033-295X.96.3.506

Triandis, H. C. (1995). Individualism and collectivism. Boulder, CO: Westview.

Triandis, H. C., Chan, D. K. S., Bhawuk, D. P., Iwao, S., \& Sinha, J. B. (1995). Multimethod probes of allocentrism and idiocentrism. International Journal of Psychology, 30, 461-480. https://doi.org/10.1080/00207599508246580

Wallbott, H. G., \& Scherer, K. R. (1995). Cultural determinants in experiencing shame and guilt. In J. Tangney and Guilford Press. In J. Tangney \& K. Fischer (Eds.), Self- 
conscious emotions: The psychology of shame, guilt, embarrassment, and pride (pp. 465-488). New York: Guilford.

Weiner, B. (1992). Human motivation: Metaphors, theories, and research. Beverly Hills, CA: Sage.

Wicker, F. W., Payne, G. C., \& Morgan, R. D. (1983). Participant descriptions of guilt and shame. Motivation and Emotion, 7, 25-39. https://doi.org/10.1007/BF00992963

Wollheim, R. (1999). On the emotions. New Haven, CT: Yale University Press.

Wong, Y., \& Tsai, J. (2007). Cultural models of shame and guilt. In J. L. Tracy, R. W. Robins, \& J. P. Tangney (Eds.), The self-conscious emotions: Theory and research (209-223). New York: Guilford. 